\title{
Investigation of the cognition and attitude of the public towards the disposal of discarded face masks during the COVID-19 pandemic
}

\section{Fanghua Li}

Department of Nursing, Shandong Mental Health Center, Jinan, China

\section{Yanqi Zhang}

School of Nursing, Cheeloo College of Medicine, Shandong University, Jinan, China

Hong Ji ( $\sim$ honghongji-2005@163.com )

Quality Control Office, The First Affiliated Hospital of Shandong First Medical University, Jinan, China.

\section{Dong Yang}

Department of Joint SThird Hospital of Jinan, Jinan, China

\section{Aiqing Wang}

Department of Nursing, Shandong Mental Health Center, Jinan, China

\section{Chang'e Li}

Obstetrics Department, The First Affiliated Hospital of Shandong First Medical University, Jinan, China.

\section{Yan Wu}

Department of Joint Surgery, The First Affiliated Hospital of Shandong First Medical University, Jinan, China.

\section{Research Article}

Keywords: COVID-19, discarded face masks, disposal, public attitude, public cognition

Posted Date: August 27th, 2020

DOI: https://doi.org/10.21203/rs.3.rs-63684/v1

License: (a) (1) This work is licensed under a Creative Commons Attribution 4.0 International License. Read Full License 


\section{Abstract}

Background: Public perception of the disposal of discarded face masks during the Coronavirus Disease 2019 (COVID-19) pandemic remains unknown. Therefore, this study aimed to assess the cognition level and attitude of the public towards the disposal of discarded face masks during the COVID-19 pandemic, to provide a reference for a standardized disposal of discarded face masks.

Methods: The convenience sampling method was applied to conduct a questionnaire survey, assessing personal general information, as well as the management status of, attitudes towards and cognition of the disposal of discarded face masks.

Results: A total of 910 valid questionnaires were collected. The results showed that $47 \%$ of individuals had a low level of relevant knowledge about the disposal of discarded face masks, but more than $95 \%$ showed a positive attitude towards the cooperation with it. In addition, the participants had limited understanding of related regulations, and expected that the relevant departments should increase publicity and training to propagate the related information.

Conclusions: This study demonstrated variations in public cognition level and attitude towards the disposal of discarded face masks during the COVID-19 pandemic. Therefore, relevant departments should further clarify the refuse classification of and management regulations for discarded face masks, increase publicity, guide the public to correctly dispose of discarded face masks and enforce supervision, to prevent viral spread and secondary environmental contamination incidents, and to ensure public health and ecological environment safety.

\section{Introduction}

Severe acute respiratory syndrome corona virus 2 (SARS-CoV-2), also known as COVID-19, was originally detected in Wuhan City in China and is now considered a pandemic [1-6]. This disease is mainly transmitted through respiratory droplets and person-to-person contact [7-9]. Preventive measures have been proposed, including frequent hand washing and sanitizing, social distancing, increasing casedetection contact tracing, quarantine and face masks [10-13]. With the development of the pandemic, public awareness of protection has increased, and wearing masks has become an important way for the public to protect themselves. The widespread use of face masks has led to shortage [14,15], although the daily production capacity and output in China have rapidly and steadily increased, both breaking through 100 million[16].

Such intensive use results in large amounts of discarded face masks, which may carry multiple viruses, bacteria and other microorganisms $[17,18]$. During a respiratory pandemic or epidemic, whether used face masks are disposed of properly can affect not only the health of involved individuals, but also the protection of the whole public. Indeed, improper mask disposal would negatively impact prevention [19]. On January 28, 2020, the Chinese Ministry of Ecology and Environment issued "Emergency management and technical guide for the disposal of medical waste under the epidemic of novel coronavirus 
pneumonia" to guide all local authorities to timely, orderly, efficiently and harmlessly dispose of medical wastes under the current pandemic. Relevant local departments subsequently issued regulations on medical waste disposal, strengthening the management of medical wastes, sewage and discarded face masks during the COVID-19 outbreak.

However, to our best knowledge, there was no study investigating public perception of the disposal of discarded face masks during the COVID-19 pandemic. Therefore, the present study aimed to assess the cognition level and attitude of the public towards the disposal of discarded face masks during the COVID-19 pandemic, to provide a reference for ameliorating the standardized disposal of discarded face masks. The findings could help improve public safety throughout the disposal of discarded face masks, prevent secondary pollution caused by improper disposal, and reduce the potential adverse effects of disposal on the epidemic prevention.

\section{Materials And Methods Participants}

In this study, the convenience sampling method was used to perform a questionnaire survey. Inclusion criteria were: 1) ability to fill the questionnaire; 2) agreement to voluntarily participate. Exclusion criteria were: 1) no independent judgment; 2) known mental disability.

\section{Investigation methods and research tool}

A self-designed questionnaire was used with 4 dimensions (33 items), including general information, and the management status of, attitudes towards and cognition of the disposal of discarded face masks. The Cronbach's a coefficient of the questionnaire was 0.712 .

General participant information included age, gender, living conditions, education level, occupation, residence during the epidemic, physical condition and whether there were any confirmed or suspected cases of novel coronavirus pneumonia in the neighborhood.

The management status of the disposal of discarded face masks included whether there were clear regulations on the disposal of discarded face masks in the area of residence during the epidemic, whether there were special collection facilities for discarded face masks, whether there were training or publicity on disposal methods for discarded face masks and other relevant contents, the management strength regarding the disposal of discarded face masks $\varangle$ knowledge of disposal methods of discarded face masks, the sources of information on disposal of discarded face masks, expectations and suggestions.

The attitude of the public towards the disposal of discarded face masks included the willingness to acquire relevant knowledge, the concern about the dangers of discarded face masks, the cooperation 
attitude towards relevant regulations, the cognition of the necessity of unified management, satisfaction with the existing management regulations and information sources.

The cognition of the disposal of discarded face masks included the type of face masks being worn, replacement time, replacement condition and disposal method, the dangers of discarded face masks, the mastery of current relevant regulations.

\section{Data collection}

In this survey, a sophisticated electronic system was used to design the electronic version of the questionnaire. The public participated voluntarily, and the investigation data were completely confidential.

\section{Statistical analysis}

SPSS 21.0 (SPSS, USA) was used for statistical analysis. Measurement data with normal distribution were presented as mean \pm standard deviation (SD), and those with skewed distribution as median and interquartile range. Count data were presented as frequency and percentage. Independent samples t-test was performed to determine factors affecting the cognition of the disposal of discarded face masks, and multivariate analysis was carried out to identify factors independently reducing it. $P<0.05$ was considered statistically significant.

\section{Results}

\section{General information of the participants}

A total of 910 questionnaires were collected. Most of the participants were female (72.9\%). There were mostly below 60 years old (97.9\%) and college graduates (almost $90 \%$ ). They included $48.9 \%$ of individuals not working in medical or related fields. The majority of participants lived with other people; most of them were healthy and $29.67 \%$ had confirmed or suspected cases of novel coronavirus pneumonia in their neighborhood. These features are detailed in Table 1.

\section{Management status of the disposal of discarded face masks}

The results showed that during the epidemic, the residences of $47.14 \%$ of all respondents had clear regulations. Those of $38.24 \%, 45.27 \%$ and $42.3 \%$ of participants had relevant facilities for, training or publicity on the knowledge about, and strict or relatively strict management of the disposal of discarded face masks, respectively. A total of $47.69 \%$ of individuals had only general or no knowledge about the 
disposal of discarded face masks. Internet, radio and television, personal experience and feeling, and information from medical workers were the main sources of knowledge regarding the disposal of discarded face masks; besides the above sources, $44.7 \%$ and $35.82 \%$ of respondents hoped to acquire relevant knowledge through publicity materials such as posters and training seminars (Table 2 ).

\section{Attitude towards the disposal of discarded face masks}

Among the respondents, $98.68 \%$ desired to acquire relevant knowledge, $83.63 \%$ were very worried or worried about the hazards associated with large amounts of discarded face masks, and $92.49 \%$ showed a very positive or positive attitude towards cooperation with relevant regulations on the disposal of discarded face masks. A total of $47.91 \%$ of participants were not satisfied with the information sources for the disposal of discarded face masks, $61.17 \%$ were not satisfied with the management of the disposal of discarded face masks in their current residences, and $20.55 \%$ expressed obvious dissatisfaction with the management of discarded face masks in their current residences (Table 3).

\section{Cognition of the disposal of discarded face masks}

Among the respondents, $99 \%$ were aware of the hazards associated with discarded face masks, $94.3 \%$ could correctly choose face masks, and $68.3 \%$ knew the correct replacement time for face masks, although only $34.2 \%$ replaced face masks within the correct time range in real life. A total of $56.3 \%$ could take correct measures to dispose of discarded face masks in real life (Table 4).

\section{Suggestions for the disposal and management of discarded face masks}

Among the respondents, $83.74 \%, 82.64 \%, 82.09 \%$ and $78.24 \%$ suggested to clarify the refuse classification of discarded face masks, to strengthen publicity and expand advertisement channels, to actively guide and standardize the disposal of discarded face masks, and to increase collection facilities for discarded face masks, respectively (Table 5).

\section{Reasons for non-timely replacement of face masks}

Among the respondents, $83.7 \%$ lacked masks, $5.4 \%$ lacked relevant knowledge, $5.0 \%$ wanted to save face masks, and $4.3 \%$ thought there was no contamination (Table 6).

\section{Cognitive level of the disposal of discarded face masks based on participant characteristics}


Independent samples t-test showed that age, education level, clear relevant regulations, occupation, relevant facilities for the disposal of discarded face masks, management strength, lack of publicity or training, willingness to acquire relevant knowledge, and worry about the hazards associated with discarded face masks significantly affected the cognition of the disposal of discarded face masks (Table 7). Independent samples t-test was performed for comparisons

\section{Factors independently reducing the cognitive level of the disposal of discarded face masks}

Multivariate linear regression analysis showed that non-medical occupation, lack of training or publicity on the disposal of discarded face masks, and loose management were adverse factors of the cognitive level of the disposal of discarded face masks (Table 8).

\section{Discussion}

The present study revealed variations in public cognition of and attitude towards

the disposal of discarded face masks during the COVID-19 outbreak. The factors negatively affecting the cognitive level of the disposal of discarded face masks included non-medical occupation, lack of training or publicity on the disposal of discarded face masks, and loose management.

Discarded face masks and other medical waste materials may disseminate diseases, contaminate the environment, affect public health and threaten health, easily causing cross infections in medical institutions $[20,21]$. In ordinary daily life, littering discarded face masks may also bring great safety hazards. First, if face masks are recycled, processed and sold back to the market by illegal businessmen after littering, the consequences will be more terrible than the natural course of epidemic or pandemic. Secondly, face masks discarded in household trash containers expose sanitation workers, with potential odds of secondary contamination in close contact. Therefore, health authorities are concerned about face mask disposal [22]. The above questionnaire survey showed that more than $90 \%$ of respondents were aware of the hazard associated with improper disposal of discarded face masks. The cognitive level of replacement time for face masks in the participants was also high, but the proportion of those who actually replaced face masks according to current regulations was less than $60 \%$. Meanwhile, $47 \%$ of respondents had a general or no knowledge about the wearing time of face masks and their refuse classification, indicating low cognitive level of the disposal of discarded face masks. Currently, relevant departments have successively issued regulations on the management of the disposal of medical waste, strengthening the management of medical waste, sewage and discarded face masks during the COVID19 outbreak. However, $40 \%$ of all respondents were unaware of clear regulations on discarded face masks, and $45 \%$ received training and publicity for the relevant knowledge. A total of $68 \%$ individuals

obtained relevant knowledge from the internet, $56 \%$ from radio and television, and $45 \%$ from personal experience and feelings. Meanwhile, $46 \%$ were somewhat satisfied or dissatisfied with the information 
sources for the disposal of discarded face masks at this stage. This indicates that the knowledge sources were relatively homogeneous and not satisfactory, and could not meet the needs of the public for information sources. Therefore, the relevant departments should design simple publicity cartoons and play them on screens in public places such as units, communities, elevators, etc., in addition to publishing relevant contents in newspapers and magazines, conceiving publicity manuals, making simple pictures and signs for individuals with different knowledge levels, and setting up propagandists everywhere to popularize the daily knowledge on the disposal of discarded face masks. For young individuals, training could be carried out via online video conferences to diversify publicity channels, in order to strengthen publicity and enhance its effect, thereby improving the cognitive level of the public for the disposal of discarded face masks.

According to the current survey, more than $95 \%$ of respondents believed that discarded face masks need specialized disposal and unified management, and $99 \%$ desired to acquire relevant knowledge. In addition, the cognitive level of the disposal of discarded face masks varied significantly by region, culture, occupation and education level. Because of their profession, medical workers have a higher level of cognition on the disposal of medical waste compared with non-medical counterparts

[23] Among non-medical workers, civil servants, company employees and students also had a high level of cognition of the disposal of discarded face masks because they had relatively wide access to relevant information. However, farmers, retirees and unemployed individuals had relatively narrow access to relevant information, which may explain their relatively lower level of cognition of the disposal of

discarded face masks. There were improper disposal behaviors such as mask reuse and disposal of discarded face masks directly into household trash containers. However, more than $95 \%$ of respondents had a positive attitude towards cooperation with relevant regulations on the disposal of discard face masks. This calls for the relevant departments to popularize health education including contents related to the disposal of discarded face masks. In addition, based on the subjects assessed here, targeted education and correct guidance should be performed, to promote correct disposal behavior.

Face mask trashes generated by medical institutions, disease control institutions and centralized isolation places, as well as the face masks used by COVID-19 infected patients and the nursing staff should be collected strictly according to the requirements for medical waste disposal, as part of strategical actions to curve the pandemic $[24,25]$. Face masks used by the general public are suggested to be discarded by ordinary waste disposal companies; meanwhile, those from residents with fever symptoms and their families, as well as from the staff of prevention and control departments are considered hazardous wastes, which should be treated according to current requirements [26]. Some areas already have special waste containers for discarded face masks. The above survey showed that $38 \%$ of residents had special trash containers for discarded face masks in their local places of residence, $15 \%$ were unware of special trash containers in their communities, $76 \%$ discarded face masks directly into household trash containers, and $61 \%$ were somewhat satisfied or dissatisfied with the current management approach. This suggested that relevant departments should set up special trash containers 
for discarded face masks on main roads, entrances and exits of residential areas, bus stations, produce markets, shopping malls and other areas, according to population density, with clear signs and labels.

When conditions permit, pedal type flip trash containers could be used, which not only are convenient, but could also prevent cross infections and improve compliance. Meanwhile, the management personnel for these special trash containers should guide the public regarding proper use. All procedures from "collection" to "transportation" and then to "cleaning" should be strictly implemented, which also represents a further refinement and promotion of refuse classification. Units or departments capable of providing sealable plastic bags to the public during the epidemic/pandemic should instruct individuals to daily seal the bags containing discarded face masks and place them into special trash containers to reduce the spread of the virus.

The limitations of this study should be mentioned. First, the participants were from the same area, and selection bias cannot be ruled out. In addition, the sample size was relatively small, which impedes the generalizability of these findings. Finally, similar studies are scarce, and we might have missed some important parameters in this survey. Therefore, further large surveys in various regions/countries should be performed to confirm our data.

\section{Conclusions}

This study showed that the public has a positive attitude towards the disposal of discarded face masks, but the overall cognitive level remains imperfect. The cognitive level of the public regarding the disposal of discarded face masks depends on multiple influencing parameters, including individual factors, social support and sources of relevant knowledge. The relevant departments should further clarify the refuse classification of discarded face masks during and after the pandemic, set up collection facilities for discarded face masks, standardize their transportation and treatment, and intensify publicity and daily supervision, to safely, standardly, orderly and efficiently dispose of discarded face masks during the COVID-19 pandemic.

\section{List Of Abbreviations}

COVID-19: Coronavirus Disease 2019

SARS-CoV-2: Severe acute respiratory syndrome corona virus 2

SD: standard deviation

\section{Declarations}

Ethics approval and consent to participate

Not applicable 
Consent for publication

Not applicable

Availability of data and materials

The datasets used and/or analyzed during the current study are available from the corresponding author on reasonable request.

Competing interests

All authors declare that they have no any conflict of interests.

Funding

None

Authors' contributions

FHL YQZ and HJ carried out the studies, participated in collecting data, and drafted the manuscript. DY and AQW performed the statistical analysis and participated in its design. CEL and YW participated in acquisition, analysis, or interpretation of data and draft the manuscript. All authors read and approved the final manuscript.

Acknowledgements

None

The team solemnly declared that the "Investigation of the cognition and attitude of the public towards the disposal of discarded face masks during the COVID-19 pandemic" reaserch had informed consent of the participants before the study, and the participants were all voluntary.In order to protect the rights and interests of participating researchers, this study has been examined and approved by the Ethics Committee of Shandong Mental Health Center.All survey data involved in this research paper were used with the oral consent of the participants themselves. The legal liability of this statement shall be borne by this research group.

\section{References}

1. Singhal A Review of Coronavirus Disease-2019 (COVID-19). Indian J Pediatr. 2020;87:281-6.

2. Lai CC, Shih TP, Ko WC, Tang HJ, Hsueh PR. Severe acute respiratory syndrome coronavirus 2 (SARSCoV-2) and coronavirus disease-2019 (COVID-19): The epidemic and the challenges. Int J Antimicrob Agents. 2020;55:105924.

3. He X, Lau EHY, Wu P, Deng X, Wang J, Hao X, et al. Temporal dynamics in viral shedding and transmissibility of COVID-19. Nat Med. 2020;26:672-5. 
4. Sun P, Lu X, Xu C, Sun W, Pan B. Understanding of COVID-19 based on current evidence. J Med 2020.

5. The race against COVID-19. Nat Nanotechnol. 2020;15:239-40.

6. Shanmugaraj B, Siriwattananon K, Wangkanont K, Phoolcharoen Perspectives on monoclonal antibody therapy as potential therapeutic intervention for Coronavirus disease-19 (COVID-19). Asian Pac J Allergy Immunol. 2020;38:10-8.

7. Diagnosis and treatment guidelines of novel coronavirus pneumonia (fifth trial version).

8. Hui DS, E IA, Madani TA, Ntoumi F, Kock R, Dar O, et al. The continuing 2019-nCoV epidemic threat of novel coronaviruses to global health - The latest 2019 novel coronavirus outbreak in Wuhan, China. Int J Infect Dis. 2020;91:264-6

9. Zhu N, Zhang D, Wang W, Li X, Yang B, Song J, et al. A Novel Coronavirus from Patients with Pneumonia in China, 2019. N Engl J Med. 2020;382:727-33.

10. Adhikari SP, Meng S, Wu YJ, Mao YP, Ye RX, Wang QZ, et al. Epidemiology, causes, clinical manifestation and diagnosis, prevention and control of coronavirus disease (COVID-19) during the early outbreak period: a scoping Infect Dis Poverty. 2020;9:29.

11. Lai CC, Wang CY, Wang YH, Hsueh SC, Ko WC, Hsueh PR. Global epidemiology of coronavirus disease 2019 (COVID-19): disease incidence, daily cumulative index, mortality, and their association with country healthcare resources and economic status. Int J Antimicrob Agents. 2020;55:105946.

12. Zhong BL, Luo W, Li HM, Zhang QQ, Liu XG, Li WT, et al. Knowledge, attitudes, and practices towards COVID-19 among Chinese residents during the rapid rise period of the COVID-19 outbreak: a quick online cross-sectional Int J Biol Sci. 2020;16:1745-52.

13. Maclntyre CR, Cauchemez S, Dwyer DE, Seale H, Cheung P, Browne G, et Face mask use and control of respiratory virus transmission in households. Emerg Infect Dis. 2009;15:233-41.

14. Wang C, Pan R, Wan X, Tan Y, Xu L, Ho CS, et al. Immediate Psychological Responses and Associated Factors during the Initial Stage of the 2019 Coronavirus Disease (COVID-19) Epidemic among the General Population in China. Int J Environ Res Public Health. 2020;17.

15. Ma QX, Shan H, Zhang HL, Li GM, Yang RM, Chen Potential utilities of mask-wearing and instant hand hygiene for fighting SARS-CoV-2. J Med Virol. 2020.

16. Lu YN. China's daily output of face masks exceeds 100 million In: People's vol. 04; 2020.

17. Zhou SS, Lukula S, Chiossone C, Nims RW, Suchmann DB, ljaz MK. Assessment of a respiratory face mask for capturing air pollutants and pathogens including human influenza and rhinoviruses. $J$ Thorac Dis. 2018;10:2059-69.

18. Chughtai AA, Stelzer-Braid S, Rawlinson W, Pontivivo G, Wang Q, Pan Y, et Contamination by respiratory viruses on outer surface of medical masks used by hospital healthcare workers. BMC Infect Dis. 2019;19:491.

19. Advice on the use of masks in the community, during home care and in health care settings in the context of the novel coronavirus 2019-nCoV outbreak (Interim guidance).WHO/nCov/IPC_Masks/2020. 2020. 
20. Sim SW, Moey KS, Tan The use of facemasks to prevent respiratory infection: a literature review in the context of the Health Belief Model. Singapore Med J. 2014;55:160-7.

21. Deress $T$, Jemal M, Girma M, Adane K. Knowledge, attitude, and practice of waste handlers about medical waste management in Debre Markos town healthcare facilities, northwest Ethiopia. BMC Res Notes. 2019;12:146.

22. Cheng KK, Lam TH, Leung CC. Wearing face masks in the community during the COVID-19 pandemic: altruism and solidarity. Lancet.

23. Sarotra P, Medhi B, Kaushal V, Kanwar V, Gupta Y, Gupta Health care professional training in biomedical waste management at a tertiary care hospital in India. J Biomed Res. 2016;30:168-70.

24. Wang H, Wang S, Yu COVID-19 infection epidemic: the medical management strategies in Heilongjiang Province, China. Crit Care. 2020;24:107.

25. The L. COVID-19: protecting health-care workers. Lancet. 2020;395:922.

26. Zhang WM. Notice on regulating collection and disposal of discarded face masks issued by Shandong Province. dzwww.com, February 4, 2020. 2020.

\section{Tables}

Due to technical limitations, Tables 1-8 are provided in the Supplementary Files section.

\section{Supplementary Files}

This is a list of supplementary files associated with this preprint. Click to download.

- Tables.docx 